\title{
Can Brand Extension Signal Product Quality?*
}

\author{
Sridhar Moorthy ${ }^{\dagger}$ \\ Rotman School of Management, University of Toronto
}

June 1, 2010; this version December 20, 2011

${ }^{*}$ I thank the Editor, Area Editor, and referees for their comments on a previous version of the paper. The paper also benefited from prior presentation at UC-Irvine, University of Toronto, London Business School, Koç University, and the 2010 QME conference. I am especially grateful to Nanda Kumar, Jeanine MiklósThal, and Birgir Wernerfelt for their detailed comments and encouragement. This research was supported by Grant \#s 410-2005-0824 and 864-2007-0306 from the Social Sciences and Humanities Research Council of Canada.

${ }^{\dagger}$ Rotman School of Management, University of Toronto, 105 St. George St, Ontario M5S 3E6, Canada. Phone: (416) 978-6312. E-mail: moorthy@rotman.utoronto.ca. 


\begin{abstract}
This paper asks whether brand extension can serve as a signal of product quality given that it costs less than a new brand. (Existing literature has assumed either that brand extension is cost-neutral or that it costs more.) I show that it can as a Perfect Bayesian Equilibrium, but the argument is unconvincing. For one thing, the separating equilibrium is not unique; a pooling equilibrium also exists in which brand extension signals nothing. For another, the separating equilibrium relies on off-equilibrium beliefs that are poorly motivated in the model. I propose a refinement of Perfect Bayesian Equilibrium that resolves both issues. Empirical off-equilibrium beliefs requires that consumers' off-equilibrium beliefs be justifiable on the basis of their prior beliefs and their product performance observations. With empirical off-equilibrium beliefs, two necessary conditions for brand extension to signal product quality are identified: (i) consumers must perceive old and new products of the firm to be positively correlated in quality, and (ii) at least some consumers must identify with brands, and not the firm behind the brand. Even with these conditions in place, the signaling argument is fragile: firm observability of past performance diminishes brand extension's signaling capability; an arbitrarily small probability of failure for good products eliminates it. My results suggest that going forward the case for brand extension must rest on foundations other than signaling product quality.
\end{abstract}




\section{Introduction}

Brand extensions - new applications of existing brands - are almost as ubiquitous as brands. Examples abound: Arm \& Hammer, originally a baking soda, is now a toothpaste, detergent, and cat litter; Sony, a brand name created for a transistor radio in 1955, has been extended to televisions, computers, cameras, and other categories; and then there is Virgin, a brand that practically epitomizes brand extension, so much so that one observer was moved to observe that it is possible to lead a "Virgin life." ${ }^{1}$ Keller (2008) notes that "typically 80 percent to 90 percent of new products in any one year are line extensions."

Given the popularity of brand extension as a strategy, there is no dearth of theorizing on why this might be so. One obvious answer is that it is cheaper to extend a brand than build a new brand. For example, Keller (2008, p. 498) writes:

From a marketing communications perspective, one obvious advantage of introducing a new product as a brand extension is that the introductory campaign does not have to create awareness of both the brand and the new product but instead can concentrate on only the new product itself. ... Several research studies document this extension benefit. One study of 98 consumer brands in 11 markets found that successful brand extensions spent less on advertising than did comparable new-name entries. Another comprehensive study found similar results, indicating that the average advertising-tosales ratio for brand extensions was 10 percent, compared with 19 percent for new brands. ... it has been estimated that a firm can save 40 percent to 80 percent on the estimated $\$ 30$ million to $\$ 50$ million it can cost to launch a new supermarket product nationally in the United States. ${ }^{2}$

What brand extension does on the benefit side is less clear. The most commonly offered explanation is that brand extension allows the new product to benefit from the equity embedded in the brand, reducing perceived risk for consumers, and giving the new product a leg up in its efforts to establish itself. On this point, here is Keller (2008, p. 497) once again:

... with brand extensions, consumers can make inferences and form expectations about the likely composition and performance of a new product, based on what they already know about the brand itself and the extent to which they feel this information is relevant to the new product. ... For example, when Sony introduced ... Vaio, consumers may have been more likely to feel comfortable with its anticipated performance because of their experience with and knowledge of other Sony products than if the product had been branded by Sony as something completely new.

A considerable literature in marketing explores the boundaries of this argument. The basic finding is that transfer of brand perceptions from one product to another is neither automatic nor

\footnotetext{
1 "You can eat Virgin food in a Virgin hotel; drink Virgin cola; wear Virgin clothes and cosmetics; use a Virgin mobile; surf the Virgin.net; use Virgin condoms; go to a Virgin doctor; buy a car through Virgin with money from your Virgin account; get married with Virgin brides; buy your house with a Virgin mortgage; listen to Virgin radio; see Virgin-funded films in a Virgin cinema; work out in a Virgin Active gym; play Virgin video games as you go on holiday on a Virgin train or plane, stopping only to buy your Virgin vodka in duty free." (The Observer, October 15, 2000)

${ }^{2}$ See also Tauber (1988).
} 
inevitable. The key mediating variable is "fit," between the brand in its original application and the brand in its new application (Aaker and Keller 1990, Park, Milberg and Lawson 1991, Broniarczyk and Alba 1994, and Lau and Phau 2007).

In this paper I focus on another claim about brand extension's prowess, a claim bolder than the previous one. This claim originates in Wernerfelt's (1988) seminal paper on umbrella branding, and it says that brand extension can signal the quality of existing and new products. Consumers in his model start out assuming that old and new products can be "good" or "bad," independently, but after seeing the brand extension conclude that both products are good. However, Wernerfelt assumes that brand extension costs more than introducing a new brand. Cabral (2000, p. 667) and Hakenes and Peitz (2008, p. 548) have suggested that his argument depends on his unrealistic cost assumption. In Cabral's own model, which assumes cost-neutrality, and that old and new products are the same quality, brand extension's signaling capability is significantly impaired: it only increases the probability of the products being high quality. More recently, Miklós-Thal (2010), also assuming cost-neutrality, but with ex ante independence between the two products, finds that Wernerfelt's equilibrium cannot exist in her model. ${ }^{3}$

Given this state of affairs, there is a need to reexamine the theoretical case for brand extension signaling product quality under realistic assumptions. This is what I do in this paper. Specifically, I make five changes to Wernerfelt's (1988) model, each moving the model in a more realistic direction. First, instead of assuming that brand extension costs more than new brand, I assume that new brand costs more than brand extension. Second, instead of assuming that the firm's old and new product quality are independent, I allow for a general correlation between them-positive, negative or zero. Third, instead of assuming that all consumers observe the firm introducing a new brand - and can thus connect the old and new brands of the firm-I assume that some do and some don't. ${ }^{4}$ Fourth, instead of assuming that firms make brand extension decisions without knowing the performance of their previous products, I assume that firms know the performance of their previous products when making a brand extension decision. Fifth, instead of assuming that good products never perform poorly, I allow for good products to perform poorly occasionally.

I begin in Section 3 with a model that incorporates the first two changes, and show that brand extension can signal product quality even in this model. In other words, Wernerfelt's result does not depend on his unrealistic cost assumption, nor on his independence assumption - contradicting Cabral's (2000) and Hakenes and Peitz's (2008) conjecture. However, the signaling case is not entirely home free. First, existence of the separating equilibrium depends on various restrictions on the model, among them: an upper bound on brand extension's cost-advantage, and a ban on perfect positive correlation - the very condition under which Cabral (2000) obtained his result. Second, the separating equilibrium is built on off-equilibrium beliefs that are essentially arbitrary in the context of the model: they require consumers to penalize one product for the poor performance

\footnotetext{
${ }^{3}$ The empirical evidence on brand extension's signaling capability is equally inconclusive. At the anecdotal level, examples like Crystal Pepsi, Virgin Brides, and Jaguar X-Type show that many brand extensions fail even while the brands that spawned them continue to be successful in their original applications. Reddy, Holak and Bhat (1994) claim that "the failure rates of extensions approach the rates of failure of new brand introductions." Erdem's (1998) study of three brands of toothpaste and toothbrush finds a negative correlation in quality across brand extensions: a brand perceived as highest quality in one category is perceived as lowest quality in the other.

${ }^{4}$ By contrast, Cabral (2000), Hakenes and Peitz (2008) and Miklós-Thal (2010) assume that no consumer can connect the distinct brands of a firm.
} 
of another - even if they believe a priori that the products are uncorrelated or negatively correlated. Third, the separating equilibrium is not unique. A pooling equilibrium also exists in which brand extension does not signal anything. Moreover, this equilibrium is more compelling: it exists without pre-conditions, and it doesn't rely on unrealistic off-equilibrium beliefs. Standard equilibrium refinements like "intuitive" criterion and "divinity" also favor the pooling equilibrium: while the separating equilibrium satisfies the intuitive criterion, it doesn't satisfy divinity; the pooling equilibrium, on the other hand, satisfies both.

Given these observations, some readers may be tempted to conclude that the case for brand extension signaling product quality is too weak to be salvaged. Others, perhaps not: after all, the separating equilibrium does exist under a fairly broad range of parameters, and it does satisfy the intuitive criterion when it does. However, both audiences should heed the following methodological issue. Our equilibrium concept (and also that of the other papers cited above)-Perfect Bayesian Equilibrium (PBE) - and the refinement criteria that go with it were originally developed in the context of signaling games whose structure is different from the game structure we have here. There, consumers observe only the firm's actions; here, they observe not only the firm's actions (to brand extend or not), but also product performance. There, an off-equilibrium event is simply a firm deviating from its equilibrium action; here, an off-equilibrium event is a firm deviating from its equilibrium action as well as the particular product performance context in which it happens. PBE allows the modeler virtually complete freedom on how to choose these off-equilibrium beliefs. Intuitive criterion and divinity place some restrictions, in some equilibria, but not enough. The net result is that virtually any equilibrium can be justified by a suitable choice of off-equilibrium beliefs. The connection between model and outcome is severed; effectively, the model makes no predictions.

I propose a solution to the methodological problem that handles both the uniqueness issue and the prediction issue. The solution is a refinement of $\mathrm{PBE}$, tailor-made for situations in which consumers must interpret a firm's branding actions in light of product performance data. I call this criterion, "empirical off-equilibrium beliefs," and argue that in models of this sort it is desirable to ask that any equilibrium involving off-equilibrium beliefs respect this criterion. Basically, the criterion says that consumers' off-equilibrium beliefs should be empirically justifiable by the consumer. That is, they should be based on their prior beliefs, the product performance data they observe, and the data-generating process producing those observations. When faced with a deviation from the equilibrium, then, consumers should neither be optimistic nor pessimistic, but be realistic.

With empirical off-equilibrium beliefs in place, we finally get some predictions. Under the original Wernerfelt (1988) assumption of zero correlation, only the pooling equilibrium exists; the separating equilibrium is eliminated. To restore brand extension's signaling capability it is necessary that old and new product quality be positively correlated. However, positive correlation by itself is not enough. It is also necessary that there exist consumers who do not connect a new brand from the firm back to the firm. In other words, some consumers must be brand-oriented. Mercifully, this is a realistic possibility. Multiplicity of equilibria ceases to be an issue. When the separating equilibrium exists, the pooling equilibrium doesn't; when the pooling equilibrium exists, the separating equilibrium doesn't.

I go on to explore the impact of making the model even more realistic: allowing the firm to 
observe the performance of its existing products before making the brand extension decision, and allowing good products to fail occasionally. I find that observing old product performance impairs brand extension's signaling capability. Allowing good products to fail - even with the minutest of probability - eliminates it.

The last observation is a devastating dénouement. It suggests that the case for brand extension must rest on foundations other than signaling product quality. I discuss some of these ways in Section 7 .

\section{Model}

The basic framework is the same as Wernerfelt's (1988). A firm has two products, an existing one - called "old" - and a new product, called "new." The old product is already branded; on the new product a branding decision has to be made. The firm can extend its existing brand to the new product, or create a new brand. Denote the brand extension decision "B" and the new brand decision "N." Wernerfelt assumes that $\mathrm{B}$ costs more than $\mathrm{N}$, by an amount $\beta>0$; I assume that $\mathrm{N}$ costs more than B, i.e., $\beta<0$.

Both old and new products can be "good" quality ("g") or "bad" quality ("b"), exogenously, with joint probabilities as in Table $1 .^{5}$ These probabilities represent the consumers' priors about the firm's products before the branding decision; their posteriors, after seeing the brand extension decision, may, of course, be different. Note that consumers' prior assessment of the marginal probability of an old (new) product being good is $\eta \in(0,1)$. As noted earlier, Wernerfelt (1988) assumes that old and new product quality are uncorrelated, i.e., $\rho=0$. I allow $\rho \in[1-(1 / 2 \eta(1-$ $\eta)), 1]$, where $\rho=1-(1 / 2 \eta(1-\eta))$ represents perfect negative correlation.

\begin{tabular}{|l|l|}
\hline$(\mathrm{g}, \mathrm{g})$ & $\eta(\eta+\rho(1-\eta))$ \\
\hline$(\mathrm{g}, \mathrm{b})$ & $(1-\eta) \eta(1-\rho)$ \\
\hline$(\mathrm{b}, \mathrm{g})$ & $(1-\eta) \eta(1-\rho)$ \\
\hline$(\mathrm{b}, \mathrm{b})$ & $(1-\eta)(1-\eta+\rho \eta)$ \\
\hline
\end{tabular}

Table 1: Prior joint probabilities

I call each possible value of the pair, (old product quality, new product quality), a firm "type." The set of all types is $\Gamma=\{(g, g),(g, b),(b, g),(b, b)\}$. The firm knows its type, but consumers don't - the product is an experience good (Nelson 1970). Consumers observe, privately, the performance of each product after buying it; in particular, the firm doesn't observe product performance. I will relax this assumption later.

What consumers observe is a binary indicator of product performance: either the product "works" $(w)$ or it "fails" $(f)$. If a product is good, it always works; however, if it is bad, then it works only with probability $\theta \in(0,1){ }^{6}$ Product performance is thus an imperfect indicator of product quality: a failing product is bad, but a working product may be good or bad. The exogeneity of product quality and the fact that it is private information of the firm makes this an

\footnotetext{
${ }^{5}$ This distribution is the same as in Wernerfelt's working paper (Wernerfelt 1986).

${ }^{6}$ What product "works" or "fails" mean can vary depending on the product category. In a car, "fails" could refer to a "breakdown"; in a soft drink, "works" could mean "tastes good." Broadly interpreted, product performance refers to "customer satisfaction." In Section 5 I explore what happens when good products can dissatisfy consumers.
} 


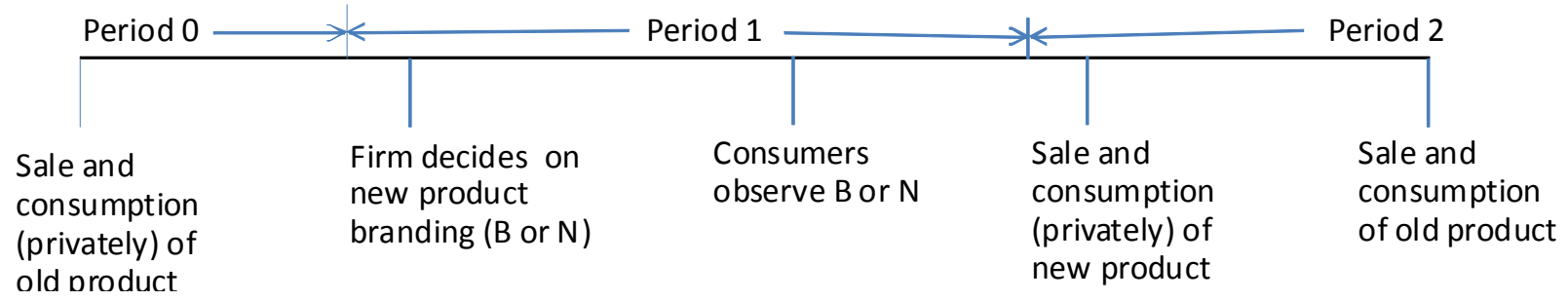

Figure 1: Timeline

"adverse selection" model (as in Cabral 2000, Miklós-Thal 2010), and not a "moral hazard" model (as in Hakenes and Peitz 2008, Cabral 2009).

The sequence of firm and consumer decisions is shown in Figure 1. Period 0 refers to the time before the brand extension decision; in this period consumers have experienced the old product, but the firm doesn't know what that experience is. In period 1 the firm makes the branding decision, anticipating the profits to come in period 2 from new and old product sales. (Sales of the old product in period 0 are irrelevant because they occur before the brand extension decision.) For the consumer, the key milestones are the dates at which she gets new information. In period 0 she buys the old product for the first time and observes its performance ( $w$ or $f$ ); in period 1 she observes whether the firm extended the brand or created a new brand (B or N); finally, in period 2 she buys the new product, observes its performance ( $w$ or $f$ ), and then buys the old product again. (Consumers' experience with the old product in period 2 is irrelevant to the firm because the model ends in period 2.) Note that consumers observe not only B, but also N. Later I will relax this assumption as well.

Denote the firm's brand extension decision as a function mapping types to probabilities of choosing B; thus $S(\tau)$ is the probability of choosing B for type $\tau \in \Gamma$. In practice, $S(\tau)$ will either be 1 or 0 , i.e., strategies will be pure strategies. Let $\Omega_{t}$ denote the consumer's information at the end of period $t$. Then $\Omega_{1}=\{i, b\}$ and $\Omega_{2}=\{i, b, j\}$ where $i=w$ or $f, b=B$ or $N$, and $j=w$ or $f(i$ and $j$ track old and new product performance, respectively). Let $P^{o} \mid \Omega_{t}$ and $P^{n} \mid \Omega_{t}$ denote consumers' perceptions of old and new product quality given information set $\Omega_{t}$. These are the posterior probabilities of the respective products being good given $\Omega_{t}$ and $S($.$) , obtained either via Bayes' rule$ or some other way (to be specified below). For instance, if $S(\tau) \equiv 1$ (as in the pooling equilibrium considered below), then $P^{n}\left|\{w, B\}=\eta+(\eta \rho(1-\eta)(1-\theta)) /(\eta+\theta(1-\eta)), P^{n}\right|\{f, B\}=\eta(1-\rho)$, $P^{o} \mid\{w, B, w\}=\left(\eta^{2}+\eta(1-\eta)(\rho+\theta(1-\rho))\right) /\left(\eta^{2}+(1-\eta)\left(\eta \rho+2 \theta \eta(1-\rho)+\theta^{2}(1-\eta+\rho \eta)\right)\right)$, $P^{o} \mid\{w, B, f\}=\eta(1-\rho) /(\eta(1-\rho)+\theta(1-\eta+\rho \eta))$, and $P^{o}\left|\{f, B, w\}=P^{o}\right|\{f, B, f\}=0 .{ }^{7}$

Let $x(P)$ denote the profit from a product perceived to be good with probability $P ; x($.$) is$ increasing, and without loss of generality I normalize $x(0)=0$ and $x(1)=1{ }^{8}$ A firm of type- $\tau$ therefore expects the profit $\sum_{i=w, f} \operatorname{Pr}(i \mid \tau) x\left(P^{n} \mid\{i, B\}\right)+\alpha \sum_{i, j=w, f} \operatorname{Pr}(i, j \mid \tau) x\left(P^{o} \mid\{i, B, j\}\right)-\beta$

\footnotetext{
${ }^{7}$ These and other posterior probabilities are derived in the Appendix.

${ }^{8}$ Effectively I am normalizing consumers' willingness to pay, for a bad product at zero, and for a good product at one. Since the former is $\theta u(w)+(1-\theta) u(f)$ and the latter is $u(w)$, this implies that $u(w)=1$ and $u(f)=-\theta /(1-\theta)$. By formulating $x$ as a function of $P$ I have side-stepped details that are of limited interest to this paper. For instance, I do not model how profits are generated, nor do I model the firm's pricing decisions. Implicitly, marginal costs are zero, so price cannot play a signaling role. See Choi (1998) for a model in which it does.
} 
following $B$, and following $N, \sum_{i=w, f} \operatorname{Pr}(i \mid \tau) x\left(P^{n} \mid\{i, N\}\right)+\alpha \sum_{i, j=w, f} \operatorname{Pr}(i, j \mid \tau) x\left(P^{o} \mid\{i, N, j\}\right)$, where $\alpha>0$ is a parameter that captures the relative importance of old versus new product to the firm.

\section{Separating and pooling equilibria}

Wernerfelt's (1988) paper, assuming $\beta>0$ and $\rho=0$, shows that brand extension can signal product quality. More specifically, he shows that a separating PBE can exist in which a firm with two good products chooses B while all other firm-types choose N; consumers, upon seeing B, infer that both old and new products are good. This equilibrium forms the basis for his assertion that brand extension can signal product quality. The question I begin with is whether the same equilibrium can exist when $\beta<0$ and $\rho$ is arbitrary.

Note first that there are two equilibrium paths of play here, one corresponding to type $(\mathrm{g}, \mathrm{g})$ 's choice of B, and the other corresponding to types (g,b), (b,g), and (b,b)'s choice of N. Offequilibrium events can happen only following $\mathrm{B}$, and they do when an old or new product fails under B (because only type ( $g, g$ ) chooses B in the equilibrium and good products are not supposed to fail). In a PBE, posterior beliefs along equilibrium paths are determined by Bayes' rule; off-equilibrium posterior beliefs are arbitrary. Here, the former are: $P^{n}\left|\{w, B\}=P^{o}\right|\{w, B, w\}=1, P^{n} \mid\{w, N\}=$ $\theta \eta(1-\rho) /(\theta+\eta(1-\rho)), P^{n}\left|\{f, N\}=\eta(1-\rho), P^{o}\right|\{w, N, w\}=\eta(1-\rho) /(2 \eta(1-\rho)+\theta(1-\eta+\rho \eta))$, $P^{o} \mid\{w, N, f\}=\eta(1-\rho) /(\eta(1-\rho)+\theta(1-\eta+\rho \eta))$, and $P^{o}\left|\{f, N, w\}=P^{o}\right|\{f, N, f\}=0$. I specify the off-equilibrium beliefs as: (1) if the old product fails in period 0 , then consumers believe that the new product is good with probability $\psi$, and the old product is good with probabilities $\varphi^{\prime}$ and $\varphi^{\prime \prime}$ depending on whether the new product works or fails, respectively, i.e., $P^{n} \mid\{f, B\}=\psi$, $P^{o}\left|\{f, B, w\}=\varphi^{\prime}, P^{o}\right|\{f, B, f\}=\varphi^{\prime \prime}$, and (2) if the old product works in period 0 but the new product fails in period 1 , then consumers believe that the old product is good with probability

$\varphi$, i.e., $P^{o} \mid\{w, B, f\}=\varphi$. These are generalizations of Wernerfelt's (1988) off-equlibrium belief structure: he assumes $\varphi=\varphi^{\prime}=\varphi^{\prime \prime}=0$.

Let $\pi(B ; i, j)(\pi(N ; i, j))$ denote the firm's expected profit when it chooses B (respectively $\mathrm{N}$ ) and its type is $(i, j)$. The separating equilibrium exists if and only if the following inequalities are satisfied:

$$
\begin{aligned}
\pi(B ; g, g)= & x(1)(1+\alpha)-\beta \geq x\left(P^{n} \mid\{w, N\}\right)+\alpha x\left(P^{o} \mid\{w, N, w\}\right)=\pi(N ; g, g) \\
\pi(B ; g, b)= & x(1)(1+\alpha \theta)+\alpha(1-\theta) x(\varphi)-\beta \leq x\left(P^{n} \mid\{w, N\}\right)+ \\
& \alpha\left[\theta x\left(P^{o} \mid\{w, N, w\}\right)+(1-\theta) x\left(P^{o} \mid\{w, N, f\}\right)\right]=\pi(N ; g, b) \\
\pi(B ; b, g)= & x(1) \theta(1+\alpha)+(1-\theta)\left(x(\psi)+\alpha x\left(\varphi^{\prime}\right)\right)-\beta \leq \theta x\left(P^{n} \mid\{w, N\}\right)+ \\
& (1-\theta) x\left(P^{n} \mid\{f, N\}\right)+\alpha \theta x\left(P^{o} \mid\{w, N, w\}\right)=\pi(N ; b, g) \\
\pi(B ; b, b)= & x(1) \theta(1+\alpha \theta)+(1-\theta)\left[x(\psi)+\alpha \theta\left(x\left(\varphi^{\prime}\right)+x(\varphi)\right)+\alpha(1-\theta) x\left(\varphi^{\prime \prime}\right)\right]-\beta \leq \\
& \theta x\left(P^{n} \mid\{w, N\}\right)+(1-\theta) x\left(P^{n} \mid\{f, N\}\right)+ \\
& \alpha \theta\left[\theta x\left(P^{o} \mid\{w, N, w\}\right)+(1-\theta) x\left(P^{o} \mid\{w, N, f\}\right)\right]=\pi(N ; b, b)
\end{aligned}
$$


The right-hand side of inequality (4) is larger, and the left-hand-side smaller (ignoring terms involving off-equilibrium beliefs), than the corresponding sides of inequality (3). So the binding inequalities are the first three. Is it possible to satisfy them by a suitable choice of off-equilibrium beliefs? Note that satisfying (1) is not an issue: it is satisfied generically as a strict inequality because $P^{n} \mid\{w, N\}$ and $P^{o} \mid\{w, N, w\}$ are both less than 1 and $x($.$) is monotonically increasing. As$ for the remaining two inequalities, it is possible to satisfy them as long as $\beta$ is not too negative. Consider the following example:

Example $1 x(y) \equiv y, \eta=2 / 3, \theta=1 / 8, \alpha=2$.

Let $\varphi=\varphi^{\prime}=\varphi^{\prime \prime}=0$ and $\psi<.39$. Then all inequalities are strictly satisfied for $\beta=0$ and $\rho=0$, and by continuity, also for $\beta<0,|\beta|$ small, and $\rho<0, \rho>0,|\rho|$ small. In other words, the separating equilibrium can exist for positive, negative or zero correlation even if brand extension costs less than a new brand, contradicting Cabral's (2000, p. 667) and Hakenes and Peitz's (2008, p. 548) conjecture.

The key ideas behind this construction are, first, that in order to satisfy (2), it is necessary that $\alpha(1-\theta)\left[x\left(P^{o} \mid\{w, N, f\}\right)-x(\varphi)\right]$ be large; otherwise, this inequality will fail because the first two terms on the left-hand side are larger than the corresponding two terms on the right-hand side. This means: (i) the old product's sales in period 2 should matter, (ii) there should be significant risk that the new product might fail when bad, and (iii) the posterior probability of the old product being good given new product failure under $\mathrm{N}$ should be large relative to the off-equilibrium probability $\varphi$ assigned to that possibility under B. Note, in particular, that $\varphi<x\left(P^{o} \mid\{w, N, f\}\right.$ is necessary. This is impossible if $\rho=1$ because then $P^{o} \mid\{w, N, f\}=0$. In other words, the products can't be perfectly positively correlated. Given $\rho<1$, existence of a separating equilibrium requires adverse belief spillovers from the new product to the old when the new product fails under $\mathrm{B}$ - even if consumers believe a priori that the two products are uncorrelated or negatively correlated in quality. Similarly, in order to satisfy (3), it is necessary that $(1-\theta)\left[x\left(P^{n} \mid\{f, N\}\right)-x(\psi)\right]$ be large, which requires $\rho<1$, and given that, adverse belief spillovers from the old product to the new when the old product fails under B - even if consumers believe a priori that the two products are uncorrelated or negatively correlated in quality. ${ }^{9}$

Ultimately, the need to have off-equilibrium beliefs with adverse belief spillovers puts restrictions on the amount of cost advantage a brand extension can have over a new brand. Suppose $\varphi, \varphi^{\prime}$, $\varphi^{\prime \prime}$ and $\psi$ are pushed to their lowest possible levels, namely 0 . Then (2) and (3) are satisfied only if $-\beta \leq \min \left\{\begin{array}{l}\alpha(1-\theta) x\left(\frac{\eta(1-\rho)}{\eta(1-\rho)+\theta(1-\eta+\rho \eta)}\right)-\left(x(1)-x\left(\frac{\theta \eta(1-\rho)}{\theta+\eta(1-\rho)}\right)\right)-\alpha \theta\left(x(1)-x\left(\frac{\eta(1-\rho)}{2 \eta(1-\rho)+\theta(1-\eta+\rho \eta)}\right)\right) \\ (1-\theta) x(\eta(1-\rho))-\theta\left(x(1)-x\left(\frac{\theta \eta(1-\rho)}{\theta+\eta(1-\rho)}\right)\right)-\alpha \theta\left(x(1)-x\left(\frac{\eta(1-\rho)}{2 \eta(1-\rho)+\theta(1-\eta+\rho \eta)}\right)\right) .\end{array}\right.$

For $\theta$ or $\rho$ close to 1 , or $\alpha$ or $\eta$ close to 0 , no cost advantage is small enough, and a separating equilibrium will not exist. However, once $-\beta$ satisfies condition (5), then a separating equilibrium

\footnotetext{
${ }^{9}$ By contrast, adverse belief spillovers upon product failure are not necessary when $\beta>0$. For example, suppose $\rho=0$ and $\beta=[x(1)-x(\eta \theta /(\eta+\theta))]+\alpha[x(1)-x(\eta /(2 \eta+\theta(1-\eta)))]>0$. We can then specify off-equilibrium beliefs as $\varphi=(\eta /(\eta+\theta(1-\eta))), \varphi^{\prime}=\varphi^{\prime \prime}=0, \psi=\eta$, with no adverse belief spillovers, and still the inequalities are satisfied and the separating equilibrium exists.
} 
will exist because off-equilibrium beliefs featuring adverse belief spillovers can always be manufactured to satisfy inequalities (1)-(4). In Example 1 with $\rho=0$, for instance, for all values of $-\beta$ up to .342 , a separating equilibrium exists.

\section{Proposition 1}

1. A separating equilibrium in which a firm with two good products extends its brand exists if and only if $-\beta$ satisfies (5), necessary conditions for which are $\alpha>0, \eta>0, \theta<1$, and $\rho<1$.

2. Existence of a separating equilibrium is facilitated by (i) small- $\beta$, i.e., brand extension's cost advantage must be small, (ii) large $\alpha$ and $\eta$, i.e., the old product's sales in period 2 must matter and the a priori probability of the old (new) product quality being good must be high, and (iii) small $\theta$ and $\rho$, i.e., the probability that a bad product will fail must be high and the a priori correlation between old and new product quality must be small or negative.

This proposition reflects the basic tension between brand extension's cost advantage and its signaling capability. If the cost advantage is too high, all types of firm, not just firms with good products, are tempted to choose brand extension, and this, of course, negates its information value. The second part of the proposition delineates the source of brand extension's signaling power, what keeps the mimicking tendency in check. That power arises from the risk a firm with bad products takes when it extends its brand, the risk of a product failing while brand-extended, taking the other product down with it. For this risk to be meaningful, the firm needs to care about both productshence the condition involving $\alpha$. A new brand provides a way to contain these spillovers - indeed, of overturning them. When $\eta(1-\rho)$ is high - the prior probability of negative correlation between the products is high - a new brand allows the inference that "failure of a product is good news about the other product."

Existence of the separating equilibrium, even subject to the constraints imposed by Proposition 1, might be viewed as good news for brand extension's signaling capability. However, it rests on shaky foundations. For one thing, the separating equilibrium relies on off-equilibrium beliefs that are not well-motivated in the model. These beliefs require consumers to penalize one product for the failure of another regardless of the correlation between them. Left to their own devices, consumers may choose to form these beliefs based on their a priori beliefs about product quality, and their product performance observations. Second, we haven't ruled out the possibility of other equilibria where brand extension doesn't signal quality. In fact, a pooling equilibrium exists in this model in which all firm-types adopt brand extension, and as a result brand extension signals nothing. Moreover, this pooling equilibrium exists without pre-conditions.

In the pooling equilibrium, there are no off-equilibrium events following B; consumers' posterior beliefs simply follow Bayes' law: $P^{n}\left|\{w, B\}=\eta+(\eta \rho(1-\eta)(1-\theta)) /(\eta+\theta(1-\eta)), P^{n}\right|\{f, B\}=$ $\eta(1-\rho), P^{o} \mid\{w, B, w\}=\left(\eta^{2}+\eta(1-\eta)(\rho+\theta(1-\rho))\right) /\left(\eta^{2}+(1-\eta)\left(\eta \rho+2 \theta \eta(1-\rho)+\theta^{2}(1-\eta+\rho \eta)\right)\right)$, $P^{o} \mid\{w, B, f\}=\eta(1-\rho) /(\eta(1-\rho)+\theta(1-\eta+\rho \eta))$, and $P^{o}\left|\{f, B, w\}=P^{o}\right|\{f, B, f\}=0 .{ }^{10}$ The only

\footnotetext{
${ }^{10}$ In the pooling equilibrium, even though the firm's branding strategy itself involves no correlation, consumers' posterior beliefs incorporate belief spillovers due to the correlation built into the prior beliefs (as long as $\rho \neq 0$ ).
} 
off-equilibrium event is $\mathrm{N}$ itself. Typically, pooling equilibria are constructed with "pessimistic" off-equilibrium beliefs following a deviation to rule them out (see, for example, Cabral 2000). Such beliefs work here too, but I can afford to be realistic. I can assume that the off-equilibrium beliefs are the same as the on-equilibrium beliefs, i.e., $P^{n}\left|\{i, N\}=P^{n}\right|\{i, B\}, P^{o}\left|\{i, N, j\}=P^{o}\right|\{i, B, j\}$ for $i, j=w, f$, and still there will be no deviation. The argument is straightforward: if neither brand extension nor new brand provides any information about product quality to consumers, then the firm ought definitely to prefer the former - it costs less. This is a powerful and robust intuition. That is why the pooling equilibrium exists without any parameter restrictions, nor restrictions on off-equilibrium beliefs. By contrast, in the separating equilibrium this very advantage of brand extension militates against equilibrium existence: types $(\mathrm{b}, \mathrm{g}),(\mathrm{g}, \mathrm{b})$, and $(\mathrm{b}, \mathrm{b})$ are all tempted to choose brand extension partly for its cost advantage, and it takes adverse off-equilibrium belief spillovers to prevent them from succumbing to temptation.

Proposition 2 A pooling equilibrium in which all types of firm extend the brand always exists.

The separating and pooling equilibria represent two different views of the role of brand extension: in one brand extension signals product quality; in the other, it doesn't. The fact that both may exist simultaneously is not exactly a strength of the model. Perhaps the model can be salvaged if we can find good reasons to pick one equilibrium over the other. I turn to this question next.

\section{Intuitive criterion and divinity}

The standard way of dealing with multiple equilibria in signaling games is to "refine away" some equilibria via the intuitive criterion (Fudenberg and Tirole 1991, pp. 447-448) or, less commonly, the divinity criteria (Fudenberg and Tirole 1991, pp. 451-455). A PBE satisfies the intuitive criterion in our context if no type of firm could obtain a payoff higher than its equilibrium payoff if it deviates from its equilibrium action and consumers respond optimally under beliefs that rule out firm types that cannot gain from the deviation regardless of what consumers believe. Divinity criterion D1 requires, roughly speaking, that consumers disbelieve that a deviation could have come from a firm-type that gains less often (relative to its equilibrium payoff) than some other firm-type (relative to its equilibrium payoff); here "gains less often" is evaluated by looking at the set of off-equilibrium beliefs under which a type gains over its equilibrium payoff. In the Appendix I show that the separating equilibrium satisfies the intuitive criterion whenever it exists, ${ }^{11}$ but never divinity; the pooling equilibrium, however, satisfies both criteria.

Proposition 3 The separating equilibrium satisfies the intuitive criterion, but fails the divinity criterion D1. The pooling equilibrium satisfies both criteria.

Some readers may be persuaded at this point to declare the pooling equilibrium the winner based on its superior performance on the divinity criterion, and conclude that the case for brand extension signaling product quality is weak. However, others may not be willing to give up on the

\footnotetext{
${ }^{11} \mathrm{By}$ contrast, under $\beta>0$, the separating equiibrium does not automatically satisfy the intuitive criterion. Wernerfelt (1988) needs a stronger version of inequality $(2)$, that $\pi(N ; g, b)>x(1)(1+\alpha)-\beta$, as well as the assumption $x(1)(1+\theta \alpha)-\beta>\pi(N ; b, b)$, to prove that the separating equilibrium satisfies the intuitive criterion. With $\beta<0$, the first of these assumptions can never be satisfied.
} 
separating equilibrium just yet, noting that it does satisfy the intuitive criterion. I wish to argue, however, that both criteria have major weaknesses in the present context, and that neither should be given much credence.

\section{Empirical off-equilibrium beliefs}

PBE and the traditional refinement criteria that build on it were developed originally for signaling games (Fudenberg and Tirole 1991, p. 324). In these games, the "sender's" action is the only message the "receiver" receives, and an off-equilibrium event is simply a deviation - a sender action that has prior probability zero in the equilibrium. Our game structure is different. Consumers in my model observe not only the firm's branding action, but also product performance. An offequilibrium event is potentially the confluence of the two: a firm action interpreted as a deviation in a particular product performance context. For example, in the separating equilibrium, observing brand extension alone doesn't tell consumers anything about whether the firm has deviated. It is only when consumers observe the old or new product fail under brand extension that they recognize a deviation. Since product performance is governed by product quality, independent of the firm's actions, consumers are confronted with two observations to reconcile, and potentially two ways of doing so. On the one hand, they need to interpret the firm's deviation from its equilibrium action; on the other hand, they need to interpret their product performance observations. The latter they can do by applying Bayes' rule. For example, in the separating equilibrium, after seeing the old product work and the new product fail following $\mathrm{B}$, consumers with a priori beliefs that $\rho=0$ could conclude $P^{o} \mid\{w, B, f\}=\eta /(\eta+\theta(1-\eta))$ by applying Bayes' rule to the observation $\{w, f\}$; in this assessment they are simply interpreting what they have observed in light of their prior beliefs and the data-generating process producing the observations. PBE allows these beliefs, but it does not require them. In fact, it allows any posterior beliefs. In doing so, it is in effect putting all the weight on the "fact of deviation"- using the product performance observations only to establish that fact, and then promptly ignoring them-essentially throwing up its hands on being able to predict posterior beliefs in the face of Bayes' rule's impotency in dealing with zero-probability conditioning events.

Neither intuitive criterion nor divinity restrict off-equilibrium beliefs much either. The intuitive criterion asks which types would have deviated under the most favorable interpretation of the deviation, and, not surprisingly, generally the answer is either all or none, or, as in the pooling equilibrium, the "bad types." In any of these scenarios, the criterion has no bite. The divinity criterion asks whether one type of firm is more likely to have deviated than another, and if it finds such a pair, then it assigns probability zero to the less-likely-to-deviate type. In our context, it has the perverse consequence of asserting that type $(b, b)$ is more likely to deviate from the pooling equilibrium than type $(\mathrm{g}, \mathrm{g})$ even though the latter is, arguably, suffering more in the company of lesser types.

Even off-equilibrium beliefs that are clearly in contradiction of the underlying data-generating process are admitted. For instance, the intuitive criterion allows a product to be viewed as good even after it has failed, as long as the product failure is accompanied by a deviation - a "loophole" we took advantage of to pronounce the pooling equilibrium intuitive-criterion-proof. Two other 
examples are noteworthy. First, consider the situation $\rho=0$. Here, based on the underlying data-generating process, failure of one product ought not to affect consumers' perceptions of the other product. Yet, as noted earlier, the separating equilibrium requires adverse belief spillovers. Second, suppose $\rho<0$. Here, Bayes' rule applied to the failure of one product ought to enhance consumers' perceptions of the other product. Instead, the separating equilibrium requires exactly the opposite response. Effectively, the separating equilibrium becomes a synthetic construct devoid of any empirical foundation.

Ultimately, this profligacy manifests itself in a failure to reign in multiple equilibria, ${ }^{12}$ and an inability to connect outcome to model. Both lead to a loss of predictive power. Virtually any outcome is possible under any model.

I propose a refinement of PBE that deals with the multiple equilibria problem and generates clear predictions. Unlike the traditional equilibrium refinements, it fully engages the specifics of our model. I call this refinement "empirical off-equilibrium beliefs," in recognition of the empirical foundation of these beliefs.

Definition. Empirical off-equilibrium beliefs are consumers' posterior beliefs about firm type after an off-equilibrium event, obtained by Bayesian-updating their prior beliefs in light of product performance data.

Empirical off-equilibrium beliefs, by definition, are theory-neutral. They are neither optimistic, nor pessimistic, just realistic. As such, they are unsullied by the theory the modeler is trying to establish. Another way to think about empirical off-equilibrium beliefs is to put oneself in the shoes of a consumer after an off-equilibrium event. This consumer's "theory" about how the game is being played has just been contradicted. What should she believe now? In the face of discredited theory, it is natural that she turns empirical, putting her faith in her prior beliefs, and the facts she has observed.

Note that empirical-off-equilibrium-beliefs are appropriately self-limiting in scope: they have no force when the consumer's data do not contradict her a priori theory. For instance, in the separating equilibrium, if (b,g) actually chooses B, the firm has deviated, but if the old product works, there is no empirical evidence of a deviation. Under these circumstances the prior theory governs: the consumer assumes $(\mathrm{g}, \mathrm{g})$ is behind the B she sees, and turns optimistic about the new product's prospects. Only if $(\mathrm{b}, \mathrm{g})$ chooses B and the old product fails does the consumer apply empirical off-equilibrium beliefs. The consumer is not completely at odds with the theorist; in fact, she is willing to go along with the theorist as long as there is no contradictory empirical evidence.

Does empirical off-equlibrium beliefs make a difference? I will now demonstrate that it does. Not only are we led to a unique equilibrium, but also we are able to specify the conditions that determine whether that equilibrium is a separating or a pooling equilibrium. In other words, finally

\footnotetext{
${ }^{12}$ However, even PBE rules out the separating equilibrium studied by Miklós-Thal (2010). In this equilibrium types $(\mathrm{g}, \mathrm{g})$ and $(\mathrm{b}, \mathrm{b})$ choose B and the rest choose N. B signals positive correlation in qualities, but not the quality level; there are no off-equilibrium events. Such an equilibrium cannot exist under our current assumptions. The reason is, if type $(b, b)$ prefers $B$ to $N$, so will type $(b, g)$. Type $(b, g)$ has an edge over type $(b, b)$ choosing $B$ because it has a better chance of being thought of as $(g, g)$. On the other hand, type (b,b) has an edge over type (b,g) choosing $\mathrm{N}$ because new product failing is "good news" for old product perceptions - types are negatively correlated along $\mathrm{N}$. Thus, the chain of inequalities goes: $\pi(B ; b, g)>\pi(B ; b, b) \geq \pi(N ; b, b)>\pi(N ; b, g)$. Note that the correlation embedded in the firm's branding strategy overrides the a priori correlation.
} 
we have some basis for saying when to expect brand extension to signal product quality and when it can't.

\section{$5 \quad$ Brand extension under empirical off-equilibrium beliefs}

Consider the separating equilibrium first. Beliefs along the equilibrium path are the same as before; what changes are the off-equilibrium beliefs, which are now based on Bayes' rule applied to the prior beliefs and the product performance observations: $P^{n}\left|\{f, B\}=\eta(1-\rho), P^{o}\right|\{f, B, w\}=$ $P^{o} \mid\{f, B, f\}=0$, and $P^{o} \mid\{w, B, f\}=\eta(1-\rho) /(\eta(1-\rho)+\theta(1-\eta+\rho \eta))$. The consequence? The separating equilibrium is eliminated. The reason: mimicking $(\mathrm{g}, \mathrm{g})$ 's behavior is too attractive for firm-types $(\mathrm{g}, \mathrm{b}),(\mathrm{b}, \mathrm{g})$, and $(\mathrm{b}, \mathrm{b})$. Brand extension saves on the cost of creating a new brand and results in an immediate anointing of the firm as $(\mathrm{g}, \mathrm{g})$, which a new brand can never surpass - as long as the illusion of $(\mathrm{g}, \mathrm{g})$ can be maintained. But what if the old or new product were to fail? In that case, empirical off-equilibrium beliefs kick in under B, but this doesn't hurt mimicking prospects because the very same beliefs exist under $\mathrm{N}$ as well. This is because there is no difference in the consumer's sample space between B and N, following the failure of a product. In either case, if only the old product failed, the sample space is $\{(\mathrm{b}, \mathrm{g}),(\mathrm{b}, \mathrm{b})\}$; if only the new product failed, it is $\{(\mathrm{g}, \mathrm{b}),(\mathrm{b}, \mathrm{b})\}$; and if both failed, then it is $\{(\mathrm{b}, \mathrm{b})\}$. Given this, Bayesian posterior beliefs following the failure of a product will be the same under B and under N. So the first advantage proves decisive and types $(\mathrm{g}, \mathrm{b}),(\mathrm{b}, \mathrm{g})$, and $(\mathrm{b}, \mathrm{b})$ will deviate to $\mathrm{B}$.

The root of the problem is the implicit assumption that consumers are able to observe the firm choosing N. Then they are able to link the old and new products together as per Table 1 under $\mathrm{N}$ as well as under B. In reality, of course, brand extension and new brand are different in the ease with which consumers can link the various products of a firm. With brand extension, the firm itself is making explicit the tie-in; ${ }^{13}$ with new brand, the firm is making it harder to establish the tie-in. ${ }^{14}$ In the latter case, consumers will have to do the work of establishing the tie-in. Complicating this task is the possibility - indeed, probability - that a tie-in simply doesn't exist: distinct brands generally do belong to distinct firms. If the search cost of researching the corporate origin of a brand is positive, then the expected cost of establishing a tie-in can be prohibitively high - at least for some people, in some categories. In high-involvement categories, such as automobiles, probably many consumers will put in the effort to identify all the brands that belong to a firm, but in low-involvement categories such as laundry detergent, it is likely few will. In any case, from a theoretical point of view, justifying brand extension as a signal of product quality under empirical off-equilibrium beliefs requires existence of at least some consumers unable to connect a new brand to previous brands of the firm. ${ }^{15}$

Suppose a proportion $\lambda$ of consumers are like that. I call these consumers "brand-oriented," to distinguish them from "firm-oriented" consumers who can connect distinct brands of a firm. For the latter, the information sets and inference process remain the same as before and the previously calculated posterior probabilities continue to apply. For the former, the information set relevant

\footnotetext{
${ }^{13}$ Trademark laws exist precisely to protect the integrity of this tie-in.

${ }^{14}$ For instance, at the Acura website, the only references to the American Honda Motor Company appear under "Privacy Policy" and "Terms \& Conditions"—-legalistic pages that most consumers wouldn't be expected to click to.

${ }^{15}$ But, as noted earlier, we don't have to assume that no consumer is able to tie brands together (Cabral 1990, Hakanes and Peitz 2008, and Miklós-Thal 2010).
} 
to new-brand consumption is $\{\phi\}$, the null information set, and the information set relevant to old brand consumption in period 2 is $\{w\}$ or $\{f\}$-its performance in period 0 . These consumers' perception of the new brand is therefore $\eta$, the marginal probability of the new product being good, and their perception of old product quality is $\eta /(\eta+\theta(1-\eta))$ or 0 , depending on whether the old product worked or failed in period 0 . Note a basic asymmetry for brand-oriented consumers: they observe the firm choosing B, but do not observe the firm choosing N. Effectively, they are reacting to brands, not to who owns the brands, unless the firm explicitly draws attention to the linkage via brand extension.

With this reformulation, Proposition 4 shows that a separating equilibrium can exist under certain conditions, and when it does, it rules out the pooling equilibrium.

Proposition 4 Under empirical off-equilibrium beliefs, the separating equilibrium exists only if $\rho>$ 0 and $\lambda>0$. Existence of the separating equilibrium precludes existence of the pooling equilibrium, and vice-versa.

What sustains the separating equilibrium under $\rho>0$ and $\lambda>0$ is that mimicking (g,g)'s choice of B has costs as well as benefits for types $(\mathrm{g}, \mathrm{b}),(\mathrm{b}, \mathrm{g})$ and $(\mathrm{b}, \mathrm{b})$. When either the old or the new product fails, choosing $\mathrm{B}$ entails adverse belief spillovers to the other product among all consumers, while choosing $\mathrm{N}$ contains the adverse spillover to the $1-\lambda$ firm-oriented consumers. For instance, consider (g,b) choosing B versus N. With the former choice, if the new product fails, all consumers assess probability $\eta(1-\rho) /(\eta(1-\rho)+\theta(1-\eta+\rho \eta))$ that the old product is good. With the latter, only $(1-\lambda)$ fraction of the population does so; the rest cannot trace the new brand to the firm, and their assessment of the probability that the old product is good continues to be $\eta /(\eta+\theta(1-\eta))$ (a simple updating of old product perceptions based solely on its performance). Now, $\eta /(\eta+\theta(1-\eta))>\eta(1-\rho) /(\eta(1-\rho)+\theta(1-\eta+\rho \eta))$ if and only if $\rho>0$, i.e., the old and new products are positively correlated in quality a priori. So, only if $\rho>0$ and $\lambda>0$, is it possible for $(\mathrm{g}, \mathrm{b})$ to prefer $\mathrm{N}$ to $\mathrm{B}$.

In the example below, the separating equilibrium exists, and the pooling equilibrium does not.

Example $2 x(y) \equiv y, \eta=2 / 3, \theta=1 / 8, \alpha=2, \beta=-.15, \rho=.95$, and $\lambda=.9$.

The import of Proposition 4 is that for brand extension to signal old and new product quality it is necessary that consumers perceive a priori that a new product from the firm will be like its old product, and that at least some consumers will evaluate a new brand from the firm afresh without "baggage" from, or consequences to, the old brand of the firm. Note that these are necessary conditions, not sufficient conditions. The latter are identified by inequalities (6)-(9) in the Appendix. A look at these inequalities, and Example 2, ought to convince the reader that simply meeting the necessary conditions is unlikely to produce a separating equilibrium. Not only must there be a positive correlation, the correlation must be large; not only must there be brandoriented consumers, there must be a large number of them; not only must $\alpha>0, \alpha$ must be large. In addition, the probability of a bad product failing must be large because ultimately it is the down-side risk of a bad product's poor performance spilling over to other products in the brand family that dissuades non-(g,g) types from pursuing a brand extension strategy. Even with all these 
conditions in place, brand extension is still not guaranteed to signal good quality: brand extension's cost-advantage may simply be too attractive for every type of firm.

The second part of the proposition provides reassurance that in any given situation brand extension conveys a single meaning: either it signals old and new product quality or it does neither.

\subsection{Observing old product performance before brand extension}

So far I have assumed that the firm does not observe old product performance in period 0 . This is unrealistic: firms generally know how their existing products are doing when they embark on a brand extension. In this subsection I will examine whether observing old product performance affects brand extension's signaling properties. One immediate difference is that branding strategy is now a function of two things: the firm's type, and its old product period-0 performance. Whether this make a substantive difference is the issue.

Consider first the situation when the old product fails in period 0. Now the firm knows that the consumers know that the old product is bad. The only perception brand extension can influence is that of the new product. Can brand extension signal that the new product is good? The answer is no. If type $(b, g)$ finds it worthwhile to choose $\mathrm{B}$ over $\mathrm{N}$, so will type $(\mathrm{b}, \mathrm{b})$. In either case the payoff from choosing $\mathrm{B}$ is $x(1)-\beta$, and it is $\lambda x(\eta)$ from choosing $\mathrm{N}$. Only a pooling equilibrium is possible: both $(\mathrm{b}, \mathrm{g})$ and $(\mathrm{b}, \mathrm{b})$ choosing the same branding strategy, $\mathrm{B}$ or $\mathrm{N}$, depending on whether $x(\eta(1-\rho))-\beta$ or $\lambda x(\eta)+(1-\lambda) x(\eta(1-\rho))$ is larger. For $\lambda>0$, if $\rho>0$ is large and $-\beta$ not too large, then $\mathrm{N}$ might be optimal: new brand allows the firm to put some distance between its old and new products (via brand-oriented consumers) when the old product has failed.

If the old product works in period 0 , then the firm knows that consumers are still uncertain about old product quality at the time of the branding decision. All types of firm are still in play. Nevertheless, it is impossible to separate type $(\mathrm{g}, \mathrm{g})$ from the rest via brand extension: if type $(\mathrm{g}, \mathrm{g})$ prefers B to N, so will type (b,g). The reason is, a type-(b,g) firm, having successfully negotiated period 0 without revealing its old product quality, finds itself in the same position, going forward, as a type-(g,g) firm. Nor can brand extension signal old product quality alone. Now types (b,g) and $(b, b)$ find themselves in the same position as types $(g, g)$ and $(g, b)$, respectively. However, it is possible to signal new product quality alone under the same circumstances as I show in the Appendix.

Proposition 5 Under empirical off-equilibrium beliefs, when the firm observes old product performance in period 0 :

1. Brand extension cannot signal old product quality regardless of whether the old product works or fails in period 0 .

2. Brand extension can signal new product quality, but only if the old product works in period 0 , and $\rho>0, \lambda>\theta$. Existence of this separating equilibrium precludes existence of a pooling equilibrium in which all types choose brand extension, and vice-versa.

The upshot of this analysis is that brand extension's signaling capability is eroded by the firm's knowledge of its past products' performance - B can only signal $(\mathrm{g}, \mathrm{g})$ or $(\mathrm{b}, \mathrm{g})$, not $(\mathrm{g}, \mathrm{g})$. It 
underscores the importance of perceived risk in sustaining brand extension's signaling capability, a theme to which I will return in Section 6.

\subsection{What if good products also fail?}

The model so far assumes that good products never fail, so a failing product is automatically stamped as a bad product, with no possibility of redemption. One might view this as unrealistic: good products do fail, just not as often as bad products. Here I investigate what happens to the foregoing results if a good product can fail with probability $1-\vartheta \in(0,1-\theta)$.

One superficial change is that a product deemed good is now expected to yield profits of $x((\vartheta-$ $\theta) /(1-\theta))$, not $x(1)$, so a product perceived to be good with probability $P$ is expected to yield $x(P(\vartheta-\theta) /(1-\theta))$ (cf. footnote 8$)$. A more substantive change is that all off-equilibrium events are eliminated in the separating equilibrium: a product failing is no longer an indication of a bad product. In the absence of off-equilibrium events to trigger adverse belief spillovers, mimicking type $(\mathrm{g}, \mathrm{g})$ 's choice of brand extension has no downside, only an upside, for types (g,b), (b,g) and (b,b). Specifically, the posterior probabilities following B are $P^{n}\left|\{w, B\}=P^{n}\right|\{f, B\}=P^{o} \mid\{w, B, w\}=$ $P^{o}\left|\{w, B, f\}=P^{o}\right|\{f, B, w\}=P^{o} \mid\{f, B, f\}=1$. Effectively, the signal-(g,g) - smothers the product performance data. Inequalities (7)-(9) can never be satisfied, so in Proposition 4 only the pooling equilibrium can survive. Observability of period 0 performance doesn't change this conclusion. In the Appendix I show that even partial signaling is not possible.

Proposition 6 When good products can fail with positive probability, brand extension cannot signal product quality.

The sweep of this proposition is breathtaking. Even the smallest of probabilities of a good product failing - arbitrarily small — is sufficient to eliminate brand extension's signaling capabilities. Does this sound the death knell for brand extensions? I discuss this and other questions next.

\section{Discussion}

The foregoing propositions identify conditions under which brand extension can signal product quality, and conditions under which it cannot. In this section I will discuss what my results say about (i) the source of brand extension's signaling prowess, (ii) previous results in the literature, and (iii) brand extension's performance in the real-world.

At the outset it is clear that recognizing brand extension's cost advantage takes a toll on its signaling capabilities. The two motivations for brand extension are really at cross-purposes with each other. The argument is straightforward: if brand extension is significantly cheaper than new brand, then all sorts of firms - not just those with good quality products - are tempted to introduce new products as brand extensions, trading off whatever risks they might face down the road in return for the sure gain of lower cost. Propositions 4-5 delineate what those risks might be and how they manifest themselves. First, the relevant risk is the risk of collateral damage in another product in the brand portfolio should a product fail while brand-extended. The risk has to be on a different product because that is the unique risk a brand extension contributes - for the product in question, the risk is the same with or without brand extension. This explains the 
necessary conditions $\rho>0$ and $\lambda>0$, the former capturing the empirical requirement for spillovers to happen organically, and the latter placing the onus on consumers for whom brand extension is the necessary glue that connects the various products of a firm. Second, the risk of collateral damage must be felt on cash flows that arise after the next purchase of the product in question, following brand extension. This explains why, in Proposition 5, brand extension can signal new product quality, but not old product quality: the old product imposes no collateral risk following its next purchase after brand extension, whereas the new product does. The only exception to this rule is identified in Proposition 4. Here old product quality is signaled, even though its performance is observed before brand extension; this is because the firm doesn't observe this performance, only the consumer does.

These observations help put the previous literature in perspective. In Miklós-Thal 's (2010) model, $\beta=0$ and brand extension precedes two purchases of old and new products. And $\lambda=1$, so conditions are indeed ripe for brand extension to risk collateral damage and a new brand not to. Still, brand extension is unable to signal product quality. Why? One reason is that her model of product quality obviates off-equilibrium events, so Proposition 6 applies. But even if this were not so, brand extension still cannot signal product quality in her framework. The reason is, another ingredient is missing. Product qualities are ex ante independent in her model, which violates a necessary condition for signaling in Proposition 4. Interestingly, even while product quality cannot be signaled in Miklós-Thal's model, positive correlation in quality can be signaled. Firms with two good products or two bad products can separate themselves from the rest by choosing brand extension. This is possible because quality correlation is embedded in the signaling strategy itself. Now a mimicking firm, such as $(\mathrm{g}, \mathrm{b})$, is guaranteed an adverse spillover by the branding strategy itself. It can escape the spillover by choosing $\mathrm{N}$, taking advantage of the assumption $\lambda=1$. But note that our analysis reveals that if $\lambda<1$ this equilibrium may not survive: for firm-oriented consumers, $\mathrm{N}$ signals negative correlation, so type $(\mathrm{b}, \mathrm{b})$ may have an incentive to deviate from $\mathrm{B}$ to $\mathrm{N}$ (cf. footnote 12).

Cabral's (2000) model assumes $\beta=0, \rho=1$ and $\lambda=1$ with continuous quality and performance spaces, and the information structure is akin to our Section 5.1. He finds that brand extension can separate the firm's quality into an "upper" subset of the quality space. Brand extension doesn't say that a product is good, only that it is relatively good. In other words, residual uncertainty about product quality exists even after the signal. Ironically, this is what enables the signaling in the first place. A firm with relatively poor quality choosing B runs a greater risk of having both of its products evaluated toward the lower end of the "signaling interval" than a firm in the upper reaches of that interval - which risk it can avoid by choosing N. In contrast, Proposition 6 nullifies brand extension's signaling capability in our model. The reason for the difference is that quality is binary in our model, so the only signaling possibilities are "perfect" signaling possibilities. Absent residual uncertainty after the signal, the returns to mimicking are enhanced: the signal smothers the possibility of consumers learning from product performance.

Propositions 4 and 5 identify positive quality correlation as critical to a signaling role for brand extension, and this may be seen as the counterpart of "fit" from the behavioral literature (Aaker and Keller 1990; Park, Milberg and Lawson 1991). However, there is a key difference worth noting: correlation is about consumers' perceptions of the firm, whereas fit is about the product categories 
in question. In other words, the signaling view presumes that brand equity is ultimately about the actor behind the brand, not the brand itself, unlike the behavioral literature. Which of these perspectives is empirically true remains an open question. What is undeniable is that the signaling perspective puts feedback and feedforward effects of brand extension on the same plane, as two sides of the same coin. A firm must risk material damage to its brand equity for it to benefit from brand equity.

In the annals of business, there have been some instances where collateral damage across brand extensions has been demonstrated, but not many. Sullivan (1990) documents that rumors about sudden acceleration involving the Audi 5000 in 1986 not only hurt Audi 5000 sales and prices but also the sales and prices of other Audi models. On the other hand, the failure of Crystal Pepsi had little effect on other products in the Pepsi line-perhaps not surprising given the ease of direct verification of quality in soft drinks. Despite the difference in collateral damage outcomes in the two cases, our framework would argue that in neither case did brand extension benefit the new products in question going in: in the case of Crystal Pepsi because of the low probability of collateral damage; in the case of Audi, because collateral damage would probably have occurred even if the Audi 5000 had been branded differently, say as Volkswagen 5000 (Volkswagen Group owns Audi).

Since risk of collateral damage underpins the entire enterprise of signaling, one might presume that the optimal time to extend a brand is when it is new. In reality this is almost never the case. Brands are typically extended only after they have acquired substantial "brand equity" — when they are, in fact, so well-established that they do not suffer much risk of collateral damage (Sullivan 2002). Also, the signaling theory presupposes a willingness on the part of consumers to rely on indirect signals of quality. For low-ticket items, it might be easier to evaluate quality directly by trying the product; for high-ticket items, consumers may choose to rely on other information sources such as word-of-mouth or Consumer Reports. Search in any of these forms would further undermine signaling by brand extension.

\section{Conclusion}

Why is brand extension a good strategy for a new product? It isn't always, of course, but when it is, one reason has to do with its lower cost vis-à-vis new brand. Whether there is any other reason is the interesting question. In this paper I asked whether brand extension can signal product quality given its cost advantage over new brand. My answer is a qualified yes, but the qualifications are quite stringent and unrealistic. Indeed, they are so stringent and unrealistic that I am inclined to conclude that quality signaling is perhaps not the most useful way to think about how brand extensions work in the real world.

Fundamentally, this is because the first justification for brand extension works at cross-purposes with the second. If consumers derive positive meaning from a brand extension, and brand extensions are cheaper than new brands, surely all kinds of firms - not merely those with good quality products - would brand-extend? And if they do, would brand extension have any meaning?

Justifying brand extension as a signal of quality in the face of this objection requires us to identify the mechanism by which brand extension derives its signaling capability, and evaluate

its robustness. Brand extension's signaling power derives from the risk of collateral damage a 
firm faces should it brand-extend to, or from, a bad product. How to motivate such collateral damage in a theoretically appropriate way occupied some of our attention. Our solution is a new refinement of Perfect Bayesian Equilibrium: "empirical off-equilibrium beliefs." This criterion says that consumers' off-equilibrium beliefs should respect their prior beliefs and what they have observed about product performance. With this methodological innovation in place, I was able to identify the necessary conditions for brand extension to signal product quality. One condition is that consumers should believe a priori that the firm's products are positively correlated in quality. Another is that at least some consumers in the market must be brand-oriented-people who will provide a measure of insulation from collateral damage. Even if these necessary conditions are satisfied, Propositions 5 and 6 show that two other features of real-world markets can completely emasculate brand extension's signaling capability.

Despite this gloomy message, it is heartening to keep in mind that brand extension is a good strategy for many reasons, signaling quality being only one. Foremost among these reasons is its effectiveness in giving a new product an immediate boost in awareness and familiarity, a key launching pad for future success. Also non-controversial is the role of brand extension in transferring certain brand associations automatically, unmediated by inferences (Sappington and Wernerfelt 1985; Pepall and Richards 2002, Lau and Phau 2007). For example, imagery, personality, and positioning transfer in this way. But we need not even shy away from inferences. Nothing in our propositions rules out a new brand extension benefiting from the accumulated reputation of existing products, and contributing to that reputation in turn. In fact, such transfers are fully envisaged in our pooling equilibrium. In this equilibrium brand extension's sole function is to connect the various products of the firm for brand-oriented consumers, allowing the performance of each product to shape their beliefs about itself as well as feed into their beliefs about other products. For a firm making good products, this pooling equilibrium will eventually result in good outcomes - a posterior distribution concentrated on the true quality of the firm's products. What our theory is really ruling out is the instantaneous anointing of a firm as "good" just because it extended its brand. Let product performance build the brand is what we are saying. 


\section{Appendix}

Posterior probabilities along equilibrium paths: separating and pooling equilibria in

Section 3. In the separating equilibrium, the posterior beliefs along the equilibrium paths are

$$
\begin{aligned}
P^{n} \mid\{w, B\} & =P^{o} \mid\{w, B, w\}=1 \\
P^{n} \mid\{w, N\} & =\operatorname{Pr}(b g \mid w, N) \\
& =\frac{\theta(1-\eta) \eta(1-\rho)}{\theta(1-\eta) \eta(1-\rho)+(1-\eta) \eta(1-\rho)+\theta(1-\eta)(1-\eta+\eta \rho)}=\frac{\theta \eta(1-\rho)}{\theta+\eta(1-\rho)} \\
P^{n} \mid\{f, N\} & =\frac{\operatorname{Pr}(f, N \mid b g) \operatorname{Pr}(b g)}{\operatorname{Pr}(f, N \mid b g) \operatorname{Pr}(b g)+\operatorname{Pr}(f, N \mid b b) \operatorname{Pr}(b b)} \\
& =\frac{(1-\eta) \eta(1-\rho)}{(1-\eta) \eta(1-\rho)+(1-\eta)(1-\eta+\eta \rho)}=\eta(1-\rho) \\
P^{o} \mid\{w, N, w\} & =\operatorname{Pr}(g b \mid w, N, w) \\
& =\frac{\theta(1-\eta) \eta(1-\rho)}{\theta(1-\eta) \eta(1-\rho)+\theta(1-\eta) \eta(1-\rho)+\theta^{2}(1-\eta)(1-\eta+\eta \rho)}=\frac{\eta(1-\rho)}{2 \eta(1-\rho)+\theta(1-\eta+\rho \eta)} \\
P^{o} \mid\{w, N, f\} & =\frac{\operatorname{Pr}(w, N, f \mid g b) \operatorname{Pr}(g b)}{\operatorname{Pr}(w, N, f \mid g b) \operatorname{Pr}(g b)+\operatorname{Pr}(w, N, f \mid b b) \operatorname{Pr}(b b)} \\
& =\frac{(1-\theta)(1-\eta) \eta(1-\rho)}{(1-\theta)(1-\eta) \eta(1-\rho)+\theta(1-\theta)(1-\eta)(1-\eta+\rho \eta)}=\frac{\eta(1-\rho)}{\eta(1-\rho)+\theta(1-\eta+\rho \eta)} \\
P^{o} \mid\{f, N, w\} & =P^{o} \mid\{f, N, f\}=0
\end{aligned}
$$

In the pooling equilibrium, the posterior beliefs along the equilibrium path are:

$$
\begin{aligned}
P^{n} \mid\{w, B\} & =\operatorname{Pr}(g g \text { or } b g \mid w, B) \\
& =\frac{\eta(\eta+\rho(1-\eta))+\theta(1-\eta) \eta(1-\rho)}{\eta(\eta+\rho(1-\eta))+\theta(1-\eta) \eta(1-\rho)+(1-\eta) \eta(1-\rho)+\theta(1-\eta)(1-\eta+\rho \eta)} \\
& =\eta+\frac{\eta \rho(1-\eta)(1-\theta)}{\eta+\theta(1-\eta)} \\
P^{n} \mid\{f, B\} & =\frac{\operatorname{Pr}(b g)}{\operatorname{Pr}(b g)+\operatorname{Pr}(b b)}=\eta(1-\rho) \\
P^{o} \mid\{w, B, w\} & =\operatorname{Pr}(g g \text { or } g b \mid w, B, w) \\
& =\frac{\eta(\eta+\rho(1-\eta))+\theta(1-\eta) \eta(1-\rho)}{\eta(\eta+\rho(1-\eta))+\theta(1-\eta) \eta(1-\rho)+\theta(1-\eta) \eta(1-\rho)+\theta^{2}(1-\eta)(1-\eta+\rho \eta)} \\
& =\frac{\eta^{2}+\eta(1-\eta)(\rho+\theta(1-\rho))}{\eta^{2}+(1-\eta)\left(\eta \rho+2 \theta \eta(1-\rho)+\theta^{2}(1-\eta+\rho \eta)\right)}
\end{aligned}
$$




$$
\begin{aligned}
P^{o} \mid\{w, B, f\} & =\frac{\operatorname{Pr}(g b \mid w, B, f)}{\operatorname{Pr}(g b \mid w, B, f)+\operatorname{Pr}(b b \mid w, B, f)} \\
& =\frac{(1-\theta)(1-\eta) \eta(1-\rho)}{(1-\theta)(1-\eta) \eta(1-\rho)+\theta(1-\theta)(1-\eta)(1-\eta+\rho \eta)} \\
& =\frac{\eta(1-\rho)}{\eta(1-\rho)+\theta(1-\eta+\rho \eta)} \\
P^{o} \mid\{f, B, w\} & =P^{o} \mid\{f, B, f\}=0
\end{aligned}
$$

Proof of Proposition 3. The separating equilibrium satisfies the intuitive criterion trivially because types $(b, g),(g, b)$ and $(b, b)$ will all deviate to B under favorable off-equilibrium beliefs (the lower cost of brand extension only facilitates such deviation). So the intuitive criterion has no bite. However, the separating equilibrium does not satisfy divinity. Compare types (b,b) and (b,g). The right-hand side of inequality (??) is strictly greater than the right-hand side of inequality (3), but the left-hand sides of the two inequalities - the parts independent of off-equilibrium beliefs - go the other way. So the set of off-equilibrium beliefs $\left\{\left(\psi, \varphi, \varphi^{\prime}, \varphi^{\prime \prime}\right)\right\}$ under which type $(\mathrm{b}, \mathrm{b})$ will deviate to $\mathrm{B}$ from $\mathrm{N}$ is strictly smaller than the set of off-equilibrium beliefs under which type (b,g) will deviate. D1 then requires that when consumers see B and either the old or the new product failing they ought not to believe that type $(b, b)$ deviated. Once $(b, b)$ is eliminated, B could have come only from $(\mathrm{g}, \mathrm{b})$ or $(\mathrm{b}, \mathrm{g})$. But now, following failure of the old product under $\mathrm{B}$, it must be concluded that the new product is good with probability 1, i.e., $\psi=1$, and following failure of the new product under $\mathrm{B}$, it must be concluded that the old product is good with probability 1, i.e., $\varphi=1$. This means that both $(\mathrm{b}, \mathrm{g})$ and $(\mathrm{g}, \mathrm{b})$ will deviate to $\mathrm{B}$, and the separating equilibrium falls apart.

As for the pooling equilibrium, note that the payoffs under B are the least for type $(b, b)$ followed, in order, by types $(b, g),(g, b)$, and $(g, g)$. If $|\beta|$ is sufficiently large to make type $(b, b)$ not want to deviate to $\mathrm{N}$ even under the most favorable beliefs following $\mathrm{N}$, then neither will any of the other types, and the intuitive criterion is trivially satisfied. On the other hand, if $|\beta|$ is so small that even type $(\mathrm{g}, \mathrm{g})$ will deviate to $\mathrm{N}$ under the most favorable beliefs following $\mathrm{N}$, then so will all the other types, and the intuitive criterion has no bite. In the intermediate cases, some types will deviate but not the others, but if any type deviates all lower types deviate as well. In other words, following $\mathrm{N}$, beliefs will, if anything, exclude higher types, whereas under B the pooling equilibrium doesn't exclude any type. Clearly, no deviation will occur under these circumstances, and the intuitive criterion is satisfied. The proof that the pooling equilibrium satisfies divinity criterion D1 follows along the same lines: $(\mathrm{b}, \mathrm{b})$ is more likely to deviate than $(\mathrm{b}, \mathrm{g})$, which is more likely to deviate than $(\mathrm{b}, \mathrm{g})$, and so on. So beliefs following $\mathrm{N}$ ought to favor the lower types, which is not conducive to deviation.

Proof of Proposition 4. In the separating equilibrium, firm- and brand-oriented consumers have the same beliefs following B: $P^{n}\left|\{w, B\}=P^{o}\right|\{w, B, w\}=1, P^{n} \mid\{f, B\}=\eta(1-\rho)$, $P^{o}\left|\{f, B, w\}=P^{o}\right|\{f, B, f\}=0$, and $P^{o} \mid\{w, B, f\}=\eta(1-\rho) /(\eta(1-\rho)+\theta(1-\eta+\rho \eta))$. Follow- 
ing N, firm-oriented consumers have the following beliefs: $P^{n} \mid\{w, N\}=\theta \eta(1-\rho) /(\theta+\eta(1-\rho))$, $P^{n}\left|\{f, N\}=\eta(1-\rho), P^{o}\right|\{w, N, w\}=\eta(1-\rho) /(2 \eta(1-\rho)+\theta(1-\eta+\rho \eta)), P^{o} \mid\{w, N, f\}=$ $\eta(1-\rho) /(\eta(1-\rho)+\theta(1-\eta+\rho \eta))$, and $P^{o}\left|\{f, N, w\}=P^{o}\right|\{f, N, f\}=0$, and brand-oriented consumers have the following beliefs: $P^{n}\left|\{w, N\}=P^{n}\right|\{f, N\}=\eta, P^{o}\left|\{w, N, w\}=P^{o}\right|\{w, N, f\}=$ $\eta /(\eta+\theta(1-\eta))$, and $P^{o}\left|\{f, N, w\}=P^{o}\right|\{f, N, f\}=0$. The conditions governing a separating equilibrium are:

$$
\begin{aligned}
(g, g): \quad & x(1)(1+\alpha)-\beta \geq \lambda\left[x(\eta)+\alpha x\left(\frac{\eta}{\eta+\theta(1-\eta)}\right)\right]+ \\
& (1-\lambda)\left[x\left(\frac{\theta \eta(1-\rho)}{\theta+\eta(1-\rho)}\right)+\alpha x\left(\frac{\eta(1-\rho)}{2 \eta(1-\rho)+\theta(1-\eta+\rho \eta)}\right)\right] \\
(g, b): \quad & x(1)(1+\alpha \theta)+\alpha(1-\theta) x\left(\frac{\eta(1-\rho)}{\eta(1-\rho)+\theta(1-\eta+\rho \eta)}\right)-\beta \leq \lambda\left[x(\eta)+\alpha x\left(\frac{\eta}{\eta+\theta(1-\eta)}\right)\right]+ \\
& (1-\lambda)\left[x\left(\frac{\theta \eta(1-\rho)}{\theta+\eta(1-\rho)}\right)+\alpha\left(\theta x\left(\frac{\eta(1-\rho)}{2 \eta(1-\rho)+\theta(1-\eta+\rho \eta)}\right)+\right.\right. \\
& \left.\left.(1-\theta) x\left(\frac{\eta(1-\rho)}{\eta(1-\rho)+\theta(1-\eta+\rho \eta)}\right)\right)\right] \\
(b, g): \quad & x(1) \theta(1+\alpha)+(1-\theta) x(\eta(1-\rho))-\beta \leq \lambda\left[x(\eta)+\alpha x\left(\frac{\eta}{\eta+\theta(1-\eta)}\right)\right]+ \\
& (1-\lambda)\left[\theta x\left(\frac{\theta \eta(1-\rho)}{\theta+\eta(1-\rho)}\right)+(1-\theta) x(\eta(1-\rho))+\alpha \theta x\left(\frac{\eta(1-\rho)}{2 \eta(1-\rho)+\theta(1-\eta+\rho \eta)}\right)\right] \\
(b, b): \quad & x(1) \theta(1+\alpha \theta)(1-\theta)\left[x(\eta(1-\rho))+\alpha \theta x\left(\frac{\eta(1-\rho)}{\eta(1-\rho)+\theta(1-\eta+\rho \eta)}\right)\right]-\beta \leq \lambda[x(\eta)+ \\
& \left.\alpha x\left(\frac{\eta}{\eta+\theta(1-\eta)}\right)\right]+(1-\lambda)\left[\theta x\left(\frac{\theta \eta(1-\rho)}{\theta+\eta(1-\rho)}\right)+(1-\theta) x(\eta(1-\rho))+\right. \\
& \left.\alpha \theta\left(\theta x\left(\frac{\eta(1-\rho)}{2 \eta(1-\rho)+\theta(1-\eta+\rho \eta)}\right)+(1-\theta) x\left(\frac{\eta(1-\rho)}{\eta(1-\rho)+\theta(1-\eta+\rho \eta)}\right)\right)\right]
\end{aligned}
$$

These inequalities can only be satisfied if $\lambda>0$ and $\rho>0$.

Now consider the pooling equilibrium. Firm-and brand-oriented consumers have the following beliefs following B: $P^{n}\left|\{w, B\}=\eta+(\eta \rho(1-\eta)(1-\theta)) /(\eta+\theta(1-\eta)), P^{n}\right|\{f, B\}=\eta(1-\rho)$, $P^{o} \mid\{w, B, w\}=\left(\eta^{2}+\eta(1-\eta)(\rho+\theta(1-\rho))\right) /\left(\eta^{2}+(1-\eta)\left(\eta \rho+2 \theta \eta(1-\rho)+\theta^{2}(1-\eta+\rho \eta)\right)\right)$, $P^{o} \mid\{w, B, f\}=\eta(1-\rho) /(\eta(1-\rho)+\theta(1-\eta+\rho \eta))$, and $P^{o}\left|\{f, B, w\}=P^{o}\right|\{f, B, f\}=0$. Following $\mathrm{N}$, firm-oriented consumers retain these beliefs; however, brand-oriented consumers' beliefs are the same as in the separating equilibrium (see above). Comparing the two equilibria, it is clear that posterior beliefs following B are either the same or smaller in the pooling equilibrium. So the left-hand sides of the inequalities characterizing the pooling equilibrium are smaller than the corresponding left-hand sides in the separating equilibrium. Following N, the posterior beliefs are the same or larger in the pooling equilibrium. So the right-hand sides of the inequalities in the pooling equilibrium are larger than the corresponding right-hand sides in the separating equilibrium. Since the inequalities for types $(b, g),(g, b)$, and $(b, b)$ in the pooling equilibrium are $\geq$-inequalities whereas the corresponding inequalities in the separating equilibrium are $\leq$-inequalities, it must be that only one of these sets of inequalities can hold. Hence existence of the separating equilibrium precludes existence of the pooling equilibrium, and vice-versa. 
Proof of Proposition 5. Suppose consumers and firm observe the old product working in period 0. Consider a separating equilibrium in which types $(\mathrm{g}, \mathrm{g})$ and $(\mathrm{b}, \mathrm{g})$ choose B and types $(\mathrm{g}, \mathrm{b})$ and $(b, b)$ choose N. Note that a failing new product under brand extension is off the equilibrium path. Using empirical off-equilibrium beliefs, the relevant inequalities are:

$$
\begin{aligned}
(g, g ; w),(b, g ; w): \quad & x(1)+\alpha x\left(\frac{\eta+\rho(1-\eta)}{\eta+\rho(1-\eta)+\theta(1-\eta)(1-\rho)}\right)-\beta \geq \lambda x(\eta)+ \\
& \alpha\left[\lambda x\left(\frac{\eta}{\eta+\theta(1-\eta)}\right)+(1-\lambda) x\left(\frac{\eta(1-\rho)}{\eta(1-\rho)+\theta(1-\eta+\rho \eta)}\right)\right] \\
(g, b ; w),(b, b ; w): \quad & x(1)+\alpha\left[\theta x\left(\frac{\eta+\rho(1-\eta)}{\eta+\rho(1-\eta)+\theta(1-\eta)(1-\rho)}\right)+\right. \\
& \left.(1-\theta) x\left(\frac{\eta(1-\rho)}{\eta(1-\rho)+\theta(1-\eta+\rho \eta)}\right)\right]-\beta \leq \lambda x(\eta)+ \\
& \alpha\left[\lambda x\left(\frac{\eta}{\eta+\theta(1-\eta)}\right)+(1-\lambda) x\left(\frac{\eta(1-\rho)}{\eta(1-\rho)+\theta(1-\eta+\rho \eta))}\right)\right] .
\end{aligned}
$$

The right-hand sides of the two inequalities are the same. For $\rho>0,(\eta+\rho(1-\eta)) /(\eta+\rho(1-\eta)+$ $\theta(1-\eta)(1-\rho))>\eta /(\eta+\theta(1-\eta))>\eta(1-\rho) /(\eta(1-\rho)+\theta(1-\eta+\rho \eta))$, and the first inequality is satisfied. Given $\rho>0$, the second inequality can be satisfied only if $\lambda>\theta$. Once again, as in the previous section, existence of a separating equilibrium precludes existence of a pooling equilibrium in which all types of firm choose $\mathrm{B}$, and vice-versa.

Proof of Proposition 6. Consider first the case where the firm doesn't observe old product performance in period 0 . Signaling old product quality only is impossible because if types $(\mathrm{g}, \mathrm{g})$ and $(\mathrm{g}, \mathrm{b})$ have an incentive to choose $\mathrm{B}$, so do types $(\mathrm{b}, \mathrm{g})$ and $(\mathrm{b}, \mathrm{b}): P^{o}\left|\{w, B, w\}=P^{o}\right|\{w, B, f\}=$ $P^{o}\left|\{f, B, w\}=P^{o}\right|\{f, B, f\}=1$, and $P^{n}\left|\{w, B\}=P^{n}\right|\{f, B\}=\eta+\rho(1-\eta)$. Signaling new product quality isn't possible either because if types $(\mathrm{g}, \mathrm{g})$ and $(\mathrm{b}, \mathrm{g})$ have an incentive to choose $\mathrm{B}$, so do types (g,b) and (b,b): $P^{n}\left|\{w, B\}=P^{n}\right|\{f, B\}=1, P^{o}\left|\{w, B, w\}=P^{o}\right|\{w, B, f\}=$ $\vartheta(\eta+\rho(1-\eta)) /(\vartheta(\eta+\rho(1-\eta))+\theta(1-\eta)(1-\rho))$, and $P^{o}\left|\{f, B, w\}=P^{o}\right|\{f, B, f\}=(1-\vartheta)(\eta+$ $\rho(1-\eta)) /((1-\vartheta)(\eta+\rho(1-\eta))+(1-\theta)(1-\eta)(1-\rho))$. Observing old product performance in period 0 doesn't change these conclusions because neither working nor failing old product reveals old product quality, and absent revelation of old product quality, the incentives to use brand extension are the same for types $(\mathrm{g}, \mathrm{g})$ and $(\mathrm{b}, \mathrm{g})$ on the one hand and for types $(\mathrm{g}, \mathrm{b})$ and $(\mathrm{b}, \mathrm{b})$ on the other.

\section{References}

[1] Aaker, D. A. and K. L. Keller (1990), "Consumer Evaluations of Brand Extensions," Journal of Marketing, 54 (1), 27-41.

[2] Broniarczyk, S. M. and J. W. Alba (1994), "The Importance of the Brand in Brand Extension," Journal of Marketing Research, 31 (2), 214-228.

[3] Cabral, L. M. B. (2000), "Stretching Firm and Brand Reputation," The RAND Journal of Economics, 31 (4), 658-673. 
[4] (2009), "Umbrella Branding with Imperfect Observability and Moral Hazard," International Journal of Industrial Organization, 27 (2), 206-213.

[5] Choi, J. P. (1998), "Brand Extension as Informational Leverage," Review of Economic Studies, $65(4), 655-669$.

[6] D. Fudenberg and J. Tirole (1991), Game Theory. MIT Press.

[7] Hakenes, H. and M. Peitz (2008), "Umbrella Branding and the Provision of Quality," International Journal of Industrial Organization, 26, 546-556.

[8] Keller, K. L. (2008), Strategic Brand Management: Building, Measuring and Managing Brand Equity, Prentice Hall.

[9] Lau, K. C. and I. Phau (2007), "Extending Symbolic Brands Using Their Personality: Examining Antecedents and Implications Towards Brand Image Fit and Brand Dilution, " Psychology and Marketing, 24 (5), 421-444.

[10] Miklós-Thal, J. (2010), "Linking Reputations through Umbrella Branding," Working Paper, University of Rochester.

[11] Nelson, P. (1970), "Information and Consumer Behavior, " The Journal of Political Economy, 78 (2), 311-329.

[12] Park, C. W., S. Milberg and R. Lawson (1991), "Evaluation of Brand Extensions: The Role of Product Feature Similarity and Brand Concept Consistency," The Journal of Consumer Research, 18 (2), 185-193.

[13] Pepall, L. M. and D. J. Richards (2002), "The Simple Economics of Brand Stretching," Journal of Business, 75 (July), 535-552.

[14] Reddy, S. K., S. L. Holak, and S. Bhat (1994), "To Extend or Note to Extend: Success Determinants of Line Extensions," Journal of Marketing Research, 31 (May), 243-262.

[15] Sappington, D. E. M. and B. Wernerfelt (1985), "To Brand or Not to Brand? A Theoretical and Empirical Question," The Journal of Business, 58 (3), 279-293.

[16] Sullivan, M. (1990), "Measuring Image Spillovers in Umbrella-Branded Products," The Journal of Business, 63 (3), 309-329.

[17] (1992), "Brand Extensions: When to Use Them," Management Science, 38 (June), 793-806.

[18] Tauber, E. M. (1988)," Brand Leverage: Strategy for Growth an a Cost-Control World," Journal of Advertising Research, Vol. 28 (4), 26-30.

[19] Wernerfelt, B. (1986), "Umbrella Branding as a Signal of New Product Quality: An Example of Reputational Economies of Scope," Discussion Paper No. 715, Center for Mathematical Studies in Economics and Management Science, Northwestern University. 
[20] _- (1988), "Umbrella Branding as a Signal of New Product Quality: An Example of Signalling by Posting a Bond," The RAND Journal of Economics, 19 (3), 458-466. 